\title{
Article \\ Improved Interfacial Contact for Pyramidal Texturing of Silicon Heterojunction Solar Cells
}

\author{
Ruijie Dai ${ }^{1,2,+}$, Tengzuo Huang ${ }^{1,2, \dagger}$, Weijie Zhou ${ }^{1,2}$, Jinpeng Yang ${ }^{1,2}$, Hua Zhang ${ }^{1,2}$, Fayin Yu ${ }^{1,2}$, \\ Anran Chen ${ }^{1,2, *}$, Feng Wang ${ }^{1,2}$, Jin Zhang ${ }^{1,2, *}$, Tao Sun ${ }^{1,2, *}$ and Longzhou Zhang ${ }^{2, *}$
}

1 International Joint Research Center for Optoelectronic and Energy Materials, Yunnan University, Kunming 650091, China; ruijie.dai@mail.ynu.edu.cn (R.D.); htzireael@mail.ynu.edu.cn (T.H.); weijiezhou@mail.ynu.edu.cn (W.Z.); yangjinpeng@mail.ynu.edu.cn (J.Y.); zhanghua1226@mail.ynu.edu.cn (H.Z.); 15008613536@163.com (F.Y.); wangfeng123@mail.ynu.edu.cn (F.W.)

2 School of Materials and Energy, Yunnan University, Kunming 650091, China

* Correspondence: 20170027@ynu.edu.cn (A.C.); zhangjin819@ynu.edu.cn (J.Z.); taosun8805@163.com (T.S.); 20180071@ynu.edu.cn (L.Z.)

+ These authors contributed equally to this work.

\section{check for} updates

Citation: Dai, R.; Huang, T.; Zhou, W.; Yang, J.; Zhang, H.; Yu, F.; Chen, A.; Wang, F.; Zhang, J.; Sun, T.; et al Improved Interfacial Contact for Pyramidal Texturing of Silicon Heterojunction Solar Cells. Molecules 2022, 27, 1710. https://doi.org/ $10.3390 /$ molecules 27051710

Academic Editors: Yuanfu Chen, Afang Zhang, Yiming Wang, Guankui Long and Qian Chen

Received: 29 December 2021 Accepted: 26 February 2022 Published: 5 March 2022

Publisher's Note: MDPI stays neutral with regard to jurisdictional claims in published maps and institutional affiliations.

Copyright: (C) 2022 by the authors. Licensee MDPI, Basel, Switzerland. This article is an open access article distributed under the terms and conditions of the Creative Commons Attribution (CC BY) license (https:// creativecommons.org/licenses/by/ $4.0 /)$.

\begin{abstract}
Reducing the surface reflectivity of silicon substrates is essential for preparing highperformance Si-based solar cells. We synthesized pyramid-nanowire-structured Si (Si-PNWs) antireflection substrates, which have excellent light-trapping ability ( $<4 \%$ reflectance). Furthermore, diethyl phthalate (DEP), a water-insoluble phthalic acid ester, was applied to optimize the SiPNWs/PEDOT:PSS interface; the photoelectric conversion efficiency of heterojunction solar cells was shown to increase from $9.82 \%$ to $13.48 \%$. We performed a detailed examination of the shape and optical characteristics of Si-PNWs, as well as associated photoelectric performance tests, to investigate the origin of performance improvements in Si-PNWs/PEDOT:PSS heterojunction solar cells (HSCs).
\end{abstract}

Keywords: thin films; optical materials and properties; interfaces; heterojunction solar cells

\section{Introduction}

$\mathrm{Si} /$ poly(3,4-ethylenedioxythiophene)-poly(styrenesulfonate) (PEDOT:PSS) heterojunction solar cells (HSCs) are promising candidates for commercial photovoltaic cells, as they can be fabricated using simple low-cost preparation techniques and achieve high output efficiency [1-5]. Previous studies have shown that the typical average reflectivity of traditional pyramid-textured Si substrates exceeds $12 \%$ in the $400-1000 \mathrm{~nm}$ wavelength range [6-10]. Owing to the visible light reflection characteristics of silicon nanowires (Si-NWs), combinatorial pyramid-nanowire Si substrates (denoted as Si-PNWs) offer several advantages in solar cells applications. The contact area between PEDOT:PSS and the Si substrate interface is increased, the high surface topography of villiform can significantly enhance the absorption of sunlight [11-17]. It was demonstrated that the pyramid form influenced incident light reflection and heterojunction interface properties $[11,12,18,19]$. However, detailed investigations of unique three-dimensional micro-nano-textured substrates applied in $\mathrm{Si}$ /organic HSCs are rare. It is still unclear if the texture with tiny pyramids combined with nanowires can increase the efficiency of $\mathrm{Si}$ /organic HSCs. It is critical to explore the effect of texturing pyramids with different-sized nanowires on the performance of the $\mathrm{Si} /$ organic HSCs.

In this work, we applied the chemical etching method to prepare Si-PNWs. After optimizing the synthesis procedure, the experimental results showed that our novel combinatorial Si substrates exhibited improved light absorption relative to Si substrates with a traditional micro-nano structure. In addition, the proposed substrates enhanced the photoelectric performance of $\mathrm{Si}$ /organic heterojunction solar cells, which might pave the way for Si/PEDOT:PSS HSCs to be manufactured on a large scale. 


\section{Materials and Methods}

The n-type Si wafers $(1-3 \Omega \cdot \mathrm{cm},<100>, 275 \pm 10 \mu \mathrm{m})$ were cleaned using the RCA standard method. After removing the native oxide on the surfaces by a $10 \mathrm{wt} \%$ hydrofluoric acid (HF) solution, the polished side of the wafer was textured into pyramids structure by immersing in a mixture of $4.5 \mathrm{wt} \% \mathrm{KOH}$ and $18 \mathrm{vol} \%$ IPA solutions at $85^{\circ} \mathrm{C}$ for $30 \mathrm{~min}$. Next, immersing in different concentrations of $\mathrm{AgNO}_{3}(1-9 \mathrm{mM})$ and $4.5 \mathrm{mM}$ HF mixed solution for $2 \mathrm{~min}$ to deposit a layer of silver particles. Next, etching the samples in a mixed water solution of $4.5 \mathrm{mM} \mathrm{HF}, 40 \mathrm{mM} \mathrm{H}_{2} \mathrm{O}_{2}$ at room temperature for $3 \mathrm{~min}$, the residual $\mathrm{Ag}$ nanoparticles on the nanotextured surfaces were removed by dipping in nitric acid and cleaning and blow-drying with nitrogen. The $100 \mathrm{~nm} \mathrm{Al}$ was thermally evaporated as a negative electrode and transferred to a glove box. PEDOT:PSS (Clevios PH-1000) solution was added with $5 \mathrm{wt} \%$ dimethyl sulfoxide (DMSO) and $0.2 \mathrm{wt} \%$ Triton $\mathrm{X}-100$ and stirred overnight. This mixed solution was dropped evenly onto the Si-PNWs pyramids for $20 \mathrm{~s}$, then spin-coated at $2000 \mathrm{rpm}$ for $40 \mathrm{~s}$, followed by annealing at $120^{\circ} \mathrm{C}$ for $30 \mathrm{~min}$. Then, $200 \mathrm{~nm}$ Ag-grids were thermally evaporated as an anode. Diethyl phthalate (DEP) was spin-coated upon the Ag-grids at $5000 \mathrm{rpm}$ for $60 \mathrm{~s}$, then annealed at $120{ }^{\circ} \mathrm{C}$ for $10 \mathrm{~min}$. All the characterizations involved are displayed in the Supplementary Materials.

\section{Results and Discussion}

We successfully fabricated novel Si-PNWs textured substrates. The device's structure diagram and energy band diagrams are shown in Figure $1 \mathrm{a}, \mathrm{b}$, respectively. The morphology of Si-PNWs was analyzed by scanning electron microscopy (SEM). As shown in Figure 2a, pure pyramidal texturing exhibited a relatively smooth surface. In Figure $2 \mathrm{~b}, 1 \mathrm{mM} \mathrm{AgNO}_{3}$ transformed the original surface from smooth to rough. Figure $2 \mathrm{c}$ reveals the Si-PNWs composite structure that emerges when $\mathrm{AgNO}_{3}$ is increased to $3 \mathrm{mM}$. At an $\mathrm{AgNO}_{3}$ concentration of $5 \mathrm{mM}$, the nanowires grew perpendicular to the pyramid structure, with a length of approximately $50 \mathrm{~nm}$ (Figure 2d). As the $\mathrm{AgNO}_{3}$ increased to $7 \mathrm{mM}$, the nanowires continued to grow longer, which could weaken the light trapping abilities that are key to enhancing the performance of the solar cells (Figure 2e). When the concentration was increased to $9 \mathrm{mM}$, the Si-PNWs become irregular and partially destroyed. The SEM images indicate that the nanowires prepared using $5 \mathrm{mM} \mathrm{AgNO}$ exhibited intact structures, with nanowires of suitable lengths. The reflectance was measured to characterize the antireflection characteristics of the Si-PNWs. The sample prepared using $5 \mathrm{mM} \mathrm{AgNO}_{3}$ aqueous solution showed an average reflectance of $4.68 \%$. The reflectance spectra of different texture structures of silicon are shown in Figure S3 and Figure 2e. The gradual decrease in reflectance corresponds to an increase in photon absorption, thereby increasing JSC. As the nanowires grow, the FF decreases, causing the PCE to start declining. $\mathrm{AgNO}_{3}$ (5 mM) yields a PCE as high as $12.18 \%$; however, the FF is only $60.98 \%$. We believe that this is due to the surface tension of the Si/PEDOT:PSS interface leading to poor interface contact. To address this issue, we chose the HSCs made of $5 \mathrm{mM} \mathrm{AgNO}$ as a reference device, then the diethyl phthalate (DEP) was introduced on this device for modification. The DEP coating is expected to promote interface optimization $[18,20]$. 
(a)

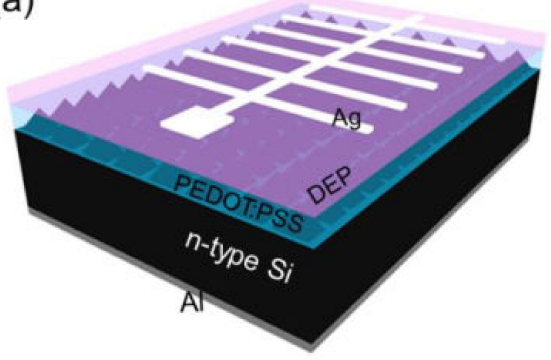

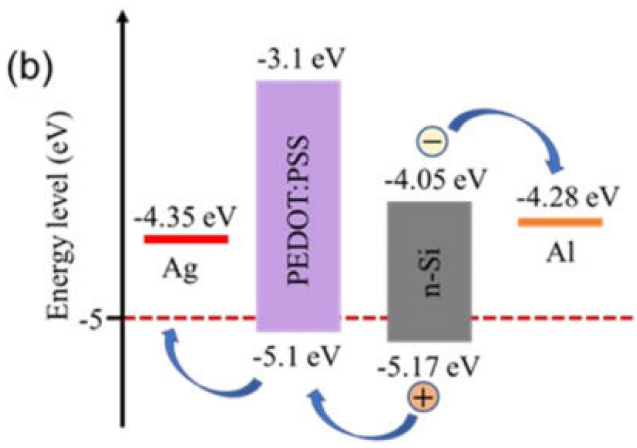

Figure 1. (a) Structure diagram of the Si-PNWs/PEDOT:PSS solar cells with DEP coating. (b) Energy band diagrams of the Si-PNWs/PEDOT:PSS solar cells.
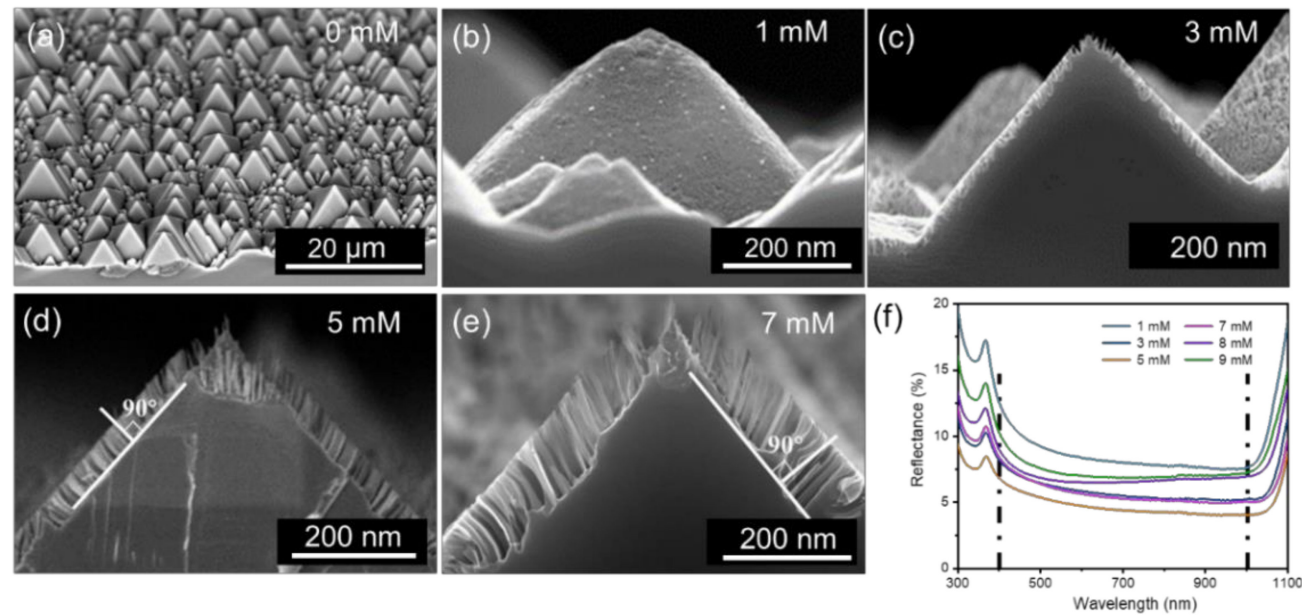

Figure 2. The devices produced using different $\mathrm{AgNO}_{3}$ concentrations (a-e) SEM images. (f) Reflectance.

It was difficult for organic matter to penetrate from the SiNWs' surface to the bottom due to the high density and the coverage was also uneven by comparing the contact between two texture structures and PEDOT: PSS (see the SEM in Figure 3a). The PEDOT layer near the tips of the SiNWs in this structure is very thin. This will lead to a low shunt resistance and thus reduced Voc and FF. The drop in Voc for cells with longer SiNWs is also attributed to higher carrier recombination associated with their increased surface area [21-24]. The defective surface of the SiNWs prepared by electroless etching and the poor infiltration and coverage of PEDOT onto the SiNW surface will exacerbate carrier recombination and lower the Voc. As compared to the SiNW cell, the SEM in Figure $3 b$ reveals that the PEDOT solution tends to flow down to the bottom edges of the base of the pyramid due to gravitational force. The organic material is in close contact with the porous silicon pyramid structure, and the thickness of the PEDOT film is homogeneous, which is important for improving hybrid solar cell device stability and conversion efficiency. Figure $3 \mathrm{c}$ shows the $\mathrm{J}-\mathrm{V}$ characteristics curves of the HSCs fabricated using different $\mathrm{AgNO}_{3}$ concentrations, in which related performance parameters (short circuit current (JSC), open-circuit voltage $\left(\mathrm{V}_{\mathrm{OC}}\right)$, fill factor (FF), photoelectric conversion efficiency (PCE)), and from 300-1000 nm are summarized in Table 1 . The light absorption was enhanced after nanowire-structure was constructed. The photoelectric properties and the average reflectance values of the differently textured silicon solar cells are listed in Table 1. 

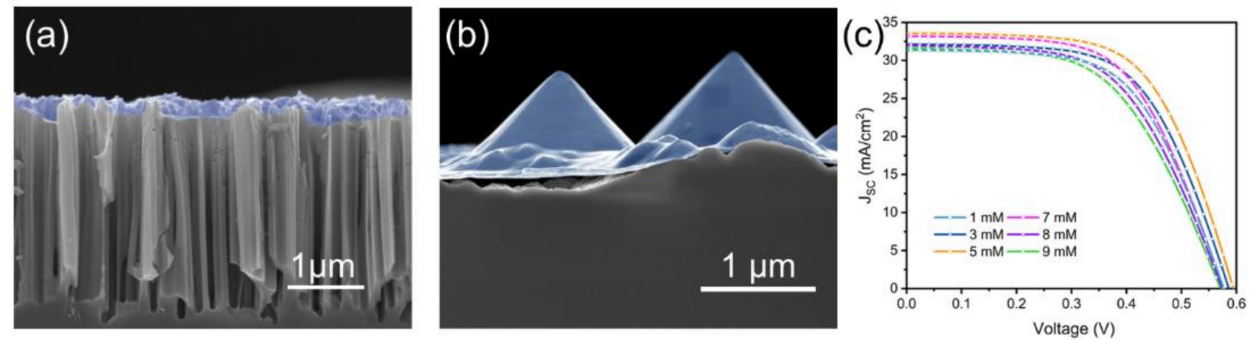

Figure 3. (a,b) SEM images of silicon nanowires and pyramids (c) $\mathrm{J}-\mathrm{V}$ curves for the $\mathrm{AgNO}_{3}$ treated Si-PNWs solar cells.

Table 1. Photoelectric property parameters and $R(\%)$ of silicon solar cells fabricated using different $\mathrm{AgNO}_{3}$ concentrations.

\begin{tabular}{cccccc}
\hline Concentration & $-\bar{R}(\mathbf{\%})$ & $\begin{array}{c}\mathbf{J}_{\mathbf{S C}} \\
\left(\mathbf{m A} / \mathbf{c m}^{\mathbf{2}}\right)\end{array}$ & $\mathbf{V}_{\text {OC }}(\mathbf{V )}$ & FF (\%) & PCE (\%) \\
\hline $1 \mathrm{mM}$ & 8.41 & 31.35 & 0.57 & 59.09 & 10.69 \\
$3 \mathrm{mM}$ & 5.79 & 32.15 & 0.58 & 69.96 & 11.30 \\
$5 \mathrm{mM}$ & 4.68 & 33.59 & 0.59 & 60.98 & 12.18 \\
$7 \mathrm{mM}$ & 5.64 & 33.19 & 0.58 & 58.40 & 11.23 \\
$8 \mathrm{mM}$ & 6.19 & 31.94 & 0.57 & 56.39 & 10.34 \\
$9 \mathrm{mM}$ & 7.28 & 31.60 & 0.57 & 55.04 & 9.85 \\
\hline
\end{tabular}

Experimental results prove that the best device with DEP coating achieves a PCE of $13.48 \%$ and an FF of $65.11 \%$. The current-voltage curve in Figure 4 a shows that the addition of the DEP coating increases the PCE of the device from $12.08 \%$ to $13.48 \%$; improving the performance of the device is mainly due to the increase in FF from $60.98 \%$ to $65.11 \%$ (Table 2). We prepared thin films of DEP and PEDOT:PSS on quartz glass to study their optical transmittance. As shown in Figure $4 b$, the transmittance of DEP coating is significantly better than that of PEDOT:PSS, implying that the introduction of DEP coating would not reduce the light absorption of the HSCs. As shown in Figure 4c, the introduction of DEP coating significantly reduces the reverse saturation current $\left(\mathrm{J}_{\mathrm{o}}\right)$, the $\mathrm{J}_{\mathrm{o}}$ can be considered to be closely related to the recombination of photogenerated carriers, and a smaller $\mathrm{J}_{\mathrm{o}}$ induces a higher $\mathrm{J}_{\mathrm{SC}}$ and $\mathrm{V}_{\mathrm{oc}}$. The reduction in $\mathrm{J}_{\mathrm{o}}$ means an improvement in the quality of the surface contact between the PEDOT:PSS thin films and the textured structure, and the defect density of the junction interface is reduced. The addition of coating layers caused conformal contact between the PEDOT: PSS film and the pyramid-textured PNWs surface, reducing interfacial re-combination losses and improving the carrier collecting capability, enhancing the charge dissociation and extraction abilities, and resulting in synergies in Voc enhancement [25-27]. In order to further prove the influence of the introduction of the DEP coating on the Si/PEDOT:PSS interface, electrochemical impedance was measured, as shown in Figure $4 \mathrm{~d}$. The substantial increase in electrochemical impedance proves that the quality of the heterojunction interface has been enhanced, which is consistent with the increase in the FF and the decrease in the reverse saturation current density [28-31]. As shown in Figure 4e, the improvement in quantum efficiency (EQE) is explained by the fact that the interface contact quality is enhanced. The Raman spectrum in Figure $4 \mathrm{f}$ shows that the energy band at $1400-1450 \mathrm{~cm}^{-1}$ is attributed to the $C_{\alpha}=C_{\beta}$ stretching vibration of the five-membered ring of PEDOT:PSS shifting to a lower energy and becoming wider [4]. This indicates that the conformation of the PEDOT:PSS chain changes from a curled to a more linear or extended curled structure after the introduction of the DEP coating, which is beneficial to the conductivity of the PEDOT:PSS thin films. On the one hand, it can induce the conformational change of PEDOT:PSS, hence increasing its conductivity. Moreover, the DEP coating produces a compressive stress on the PEDOT:PSS thin films, which effectively improves the physical contact of the Si/PEDOT:PSS interface and improves the passivation 
effect of PEDOT:PSS on the Si-PNWs substrate. In summary, introducing DEP enables the $\mathrm{Si} / \mathrm{PEDOT}: \mathrm{PSS}$ interface to establish conformal contact, effectively increasing the device FF from $60.98 \%$ to $65.11 \%$, and the PCE of the champion device reaches $13.48 \%$.

(a)
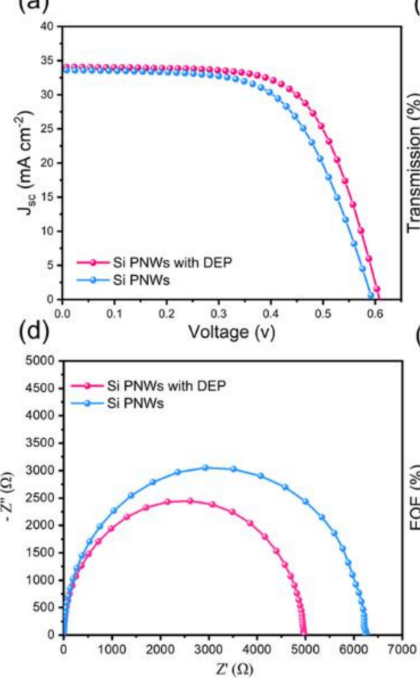

(b)

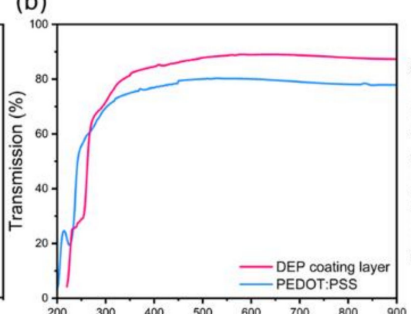

(e)

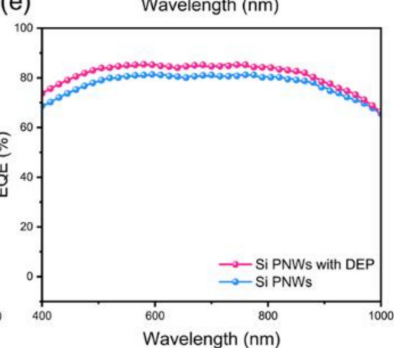

(c)
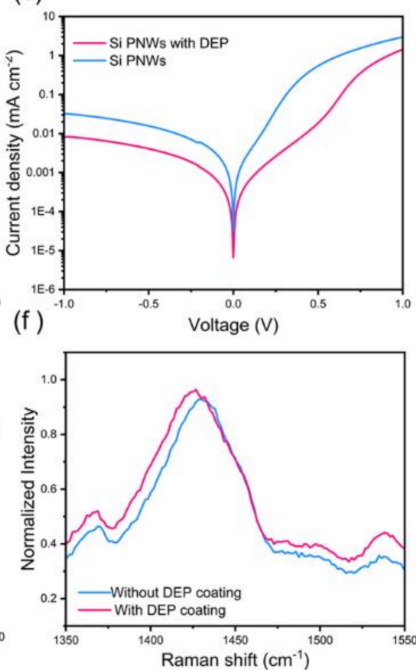

Figure 4. The devices coated with and without DEP: (a) J-V curves. (b) Reflectance. (c) Dark J-V curves. (d) Electrochemical impedance spectroscopy (EIS). (e) EQE. (f) Raman spectrum.

Table 2. Photoelectric property parameters and $R(\%)$ of devices with DEP and without DEP coating.

\begin{tabular}{|c|c|c|c|c|c|}
\hline Texture Structure & $\bar{R}(\%)$ & $\begin{array}{c}\mathrm{JSC} \\
\left(\mathrm{mA} / \mathrm{cm}^{2}\right)\end{array}$ & $\mathrm{V}_{\mathrm{OC}}(\mathrm{V})$ & FF & PCE (\%) \\
\hline Si-PNWs $w / o$ DEP & 4.68 & 33.59 & 0.59 & 60.98 & 12.18 \\
\hline Si-PNWs with DEP & 3.89 & 34.06 & 0.61 & 65.11 & 13.48 \\
\hline
\end{tabular}

\section{Conclusions}

We fabricated the Si-PNWs structure, which effectively reduced the light reflectivity while increasing the contact area. Due to surface tension, PEDOT:PSS and Si-PNWs are rather weakly contacted, resulting in the best-performing device only being able to achieve an FF of $60.98 \%$. Our work introduces DEP coatings that do not affect the light absorption of the HSCs while improving the interface contact between PEDOT:PSS and Si-PNWs, leading to an excellent PCE of $13.48 \%$ for the DEP-coated devices. DEP coating improved the surface contact quality between the PEDOT:PSS thin films and the textured structure while improving the contact between the PEDOT: PSS layer and the Ag-grids. This provides a novel strategy for the research of Si/PEDOT:PSS HSCs.

Supplementary Materials: The following supporting information can be downloaded online. Figure S1. SEM of different $\mathrm{AgNO}_{3}$ concentrations: (a) $8 \mathrm{mM}$, (b) $9 \mathrm{mM}$; Figure S2. The XRD of different structure of samples: (a) planar Si, (b) Si pyramid, (c) SiNWs, (d) Si PNWs; Figure S3. reflectance spectra of different silicon textures.

Author Contributions: Conceptualization, R.D. and W.Z.; methodology, T.H. and R.D.; software, J.Y. and H.Z.; validation, F.Y. and R.D.; formal analysis, R.D. and W.Z. investigation, R.D. and H.Z.; resources, A.C., T.S. and J.Z.; data curation, R.D. and H.Z.; writing-original draft preparation, R.D. and W.Z.; writing-review and editing, R.D. and W.Z.; visualization, R.D. and F.W.; supervision, T.S. and L.Z.; project administration, L.Z.; funding acquisition, A.C., T.S. and L.Z. All authors have read and agreed to the published version of the manuscript.

Funding: This research was funded by the YNU East-Land Scholar Research Fund (No. WX069051), the Applied Basic Research Program of Yunnan Province (No. 2015FD006) and the National Natural Science Foundation of China (No. 11274266). 
Institutional Review Board Statement: Not applicable.

Informed Consent Statement: Not applicable.

Data Availability Statement: We choose to exclude this statement as the study did not report any data.

Conflicts of Interest: The authors declare no conflict of interest.

\section{References}

1. Abdelhameed, M.; Jevasuwan, W.; Subramani, T.; Chen, J.; Fukata, N. Efficiency enhancement of Si nanostructure hybrid solar cells by optimizing non-radiative energy transfer from Si quantum dots. Nano Energy 2021, 82, 105728. [CrossRef]

2. Chen, W.; Cabarrocas, P.R.i. Rational design of nanowire solar cells: From single nanowire to nanowire arrays. Nanotechnology 2019, 30, 194002. [CrossRef] [PubMed]

3. Dai, H.; Li, M.; Li, Y.; Yu, H.; Bai, F.; Ren, X. Effective light trapping enhancement by plasmonic Ag nanoparticles on silicon pyramid surface. Opt. Express 2012, 20, A502-A509. [CrossRef] [PubMed]

4. Lu, Z.; Hou, G.; Chen, J.; Xu, J.; Chen, K. Achieving a Record Open-Circuit Voltage for Organic/Si Hybrid Solar Cells by Improving Junction Quality. Sol. RRL 2021, 5, 2100255. [CrossRef]

5. Yu, L.-M.; Man, J.-X.; Chen, T.; Luo, D.; Wang, J.; Yang, H.; Zhao, Y.-B.; Wang, H.; Yang, Y.; Lu, Z.-H. Colorful conducting polymers for vivid solar panels. Nano Energy 2021, 85, 105937. [CrossRef]

6. Fan, Q.; Zhang, Q.; Zhou, W.; Xia, X.; Yang, F.; Zhang, N.; Xiao, S.; Li, K.; Gu, X.; Xiao, Z.; et al. Novel approach to enhance efficiency of hybrid silicon-based solar cells via synergistic effects of polymer and carbon nanotube composite film. Nano Energy 2017, 33, 436-444. [CrossRef]

7. $\quad$ Fang, W.; Wang, P.; Ni, Z.; Sun, T.; Xiang, C.; Yue, K.; Wang, R.; Yang, J.; Zhou, Y.; Wang, C.; et al. Planar Organic-Si Hybrid Solar Cell with $\mathrm{MoO}_{x}$ Mixed PEDOT:PSS as Hole Injection Layer Profits from $\mathrm{Mo}^{5+}$ and $\mathrm{Mo}^{6+}$ Synergistic Effects. Adv. Mater. Interfaces 2020, 7, 2000754. [CrossRef]

8. Gong, X.; Jiang, Y.; Li, M.; Liu, H.; Ma, H. Hybrid tapered silicon nanowire/PEDOT:PSS solar cells. RSC Adv. 2015, 5, 10310-10317. [CrossRef]

9. Han, H.; Huang, Z.; Lee, W. Metal-assisted chemical etching of silicon and nanotechnology applications. Nano Today 2014, 9, 271-304. [CrossRef]

10. He, J.; Zhang, W.; Ye, J.; Gao, P. 16\% efficient silicon/organic heterojunction solar cells using narrow band-gap conjugated polyelectrolytes based low resistance electron-selective contacts. Nano Energy 2018, 43, 117-123. [CrossRef]

11. Jbira, E.; Derouiche, H.; Missaoui, K. Enhancing effect of silver nanoparticles (AgNPs) interfacial thin layer on silicon nanowires (SiNWs)/PEDOT: PSS hybrid solar cell. Sol. Energy 2020, 211, 1230-1238. [CrossRef]

12. Lee, C.-P.; Lai, K.-Y.; Lin, C.-A.; Li, C.-T.; Ho, K.-C.; Wu, C.-I.; Lau, S.-P.; He, J.-H. A paper-based electrode using a graphene dot/PEDOT:PSS composite for flexible solar cells. Nano Energy 2017, 36, 260-267. [CrossRef]

13. Li, S.; Pei, Z.; Zhou, F.; Liu, Y.; Hu, H.; Ji, S.; Ye, C. Flexible Si/PEDOT: PSS hybrid solar cells. Nano Res. 2015, 8, 3141-3149. [CrossRef]

14. Lu, W.; Wang, C.; Yue, W.; Chen, L. Si/PEDOT:PSS core/shell nanowire arrays for efficient hybrid solar cells. Nanoscale 2011, 3, 3631-3634. [CrossRef]

15. Moiz, S.A.; Alahmadi, A.N.M.; Aljohani, A.J. Design of Silicon Nanowire Array for PEDOT:PSS-Silicon Nanowire-Based Hybrid Solar Cell. Energies 2020, 13, 3797. [CrossRef]

16. Moiz, S.A.; Nahhas, A.M.; Um, H.-D.; Jee, S.-W.; Cho, H.K.; Kim, S.-W.; Lee, J.-H. A stamped PEDOT:PSS-silicon nanowire hybrid solar cell. Nanotechnology 2012, 23, 145401. [CrossRef]

17. Park, K.-T.; Kim, H.-J.; Park, M.-J.; Jeong, J.-H.; Lee, J.; Choi, D.-G.; Lee, J.-H.; Choi, J.-H. 13.2\% efficiency Si nanowire/PEDOT: PSS hybrid solar cell using a transfer-imprinted Au mesh electrode. Sci. Rep. 2015, 5, 12093. [CrossRef]

18. He, J.; Gao, P.; Yang, Z.; Yu, J.; Yu, W.; Zhang, Y.; Sheng, J.; Ye, J.; Amine, J.C.; Cui, Y. Silicon/Organic Hybrid Solar Cells with $16.2 \%$ Efficiency and Improved Stability by Formation of Conformal Heterojunction Coating and Moisture-Resistant Capping Layer. Adv. Mater. 2017, 29, 1606321. [CrossRef]

19. Jäckle, S.; Liebhaber, M.; Gersmann, C.; Mews, M.; Jäger, K.; Christiansen, S.; Lips, K. Potential of PEDOT: PSS as a hole selective front contact for silicon heterojunction solar cells. Sci. Rep. 2017, 7, 2170. [CrossRef]

20. Shen, X.; Sun, B.; Liu, D.; Lee, S.-T. Hybrid Heterojunction Solar Cell Based on Organic-Inorganic Silicon Nanowire Array Architecture. J. Am. Chem. Soc. 2011, 133, 19408-19415. [CrossRef]

21. Singh, P.; Srivastava, S.K.; Sivaiah, B.; Prathap, P.; Rauthan, C. Enhanced photovoltaic performance of PEDOT: PSS/Si solar cells using hierarchical light trapping scheme. Sol. Energy 2018, 170, 221-233. [CrossRef]

22. Sugano, Y.; Sato, K.; Fukata, N.; Hirakuri, K. Improved separation and collection of charge carriers in micro-pyramidal-structured silicon/PEDOT: PSS hybrid solar cells. Energies 2017, 10, 420. [CrossRef]

23. Sun, Z.; He, Y.; Xiong, B.; Chen, S.; Li, M.; Zhou, Y.; Zheng, Y.; Sun, K.; Yang, C. Performance-enhancing approaches for PEDOT: PSS-Si hybrid solar cells. Angew. Chem. Int. Ed. 2021, 60, 5036-5055. [CrossRef] [PubMed] 
24. Tang, Q.; Shen, H.; Yao, H.; Gao, K.; Jiang, Y.; Zheng, C.; Yang, W.; Li, Y.; Liu, Y.; Zhang, L. Potential of quasi-inverted pyramid with both efficient light trapping and sufficient wettability for ultrathin c-Si/PEDOT:PSS hybrid solar cells. Sol. Energy Mater. Sol. Cells 2017, 169, 226-235. [CrossRef]

25. Wu, S.; Cui, W.; Aghdassi, N.; Song, T.; Duhm, S.; Lee, S.-T.; Sun, B. Nanostructured Si/Organic Heterojunction Solar Cells with High Open-Circuit Voltage via Improving Junction Quality. Adv. Funct. Mater. 2016, 26, 5035-5041. [CrossRef]

26. Zhang, T.; Iqbal, S.; Zhang, X.-Y.; Wu, W.; Su, D.; Zhou, H.-L. Recent advances in highly efficient organic-silicon hybrid solar cells. Sol. Energy Mater. Sol. Cells 2020, 204, 110245. [CrossRef]

27. Zhu, J.; Yang, X.; Yang, Z.; Wang, D.; Gao, P.; Ye, J. Achieving a Record Fill Factor for Silicon-Organic Hybrid Heterojunction Solar Cells by Using a Full-Area Metal Polymer Nanocomposite Top Electrode. Adv. Funct. Mater. 2018, 28, 1705425. [CrossRef]

28. Tang, Q.; Yao, H.; Xu, B.; Ge, J. Enhanced energy conversion efficiency of Al-BSF c-Si solar cell by a novel hierarchical structure composed of inverted pyramids with different sizes. Sol. Energy 2020, 208, 1-9. [CrossRef]

29. Wang, J.; Wang, H.; Prakoso, A.B.; Togonal, A.S.; Hong, L.; Jiang, C. High efficiency silicon nanowire/organic hybrid solar cells with two-step surface treatment. Nanoscale 2015, 7, 4559-4565. [CrossRef]

30. Wang, X.; Liu, Z.; Yang, Z.; He, J.; Yang, X.; Yu, T.; Gao, P.; Ye, J. Heterojunction hybrid solar cells by formation of conformal contacts between PEDOT: PSS and periodic silicon nanopyramid arrays. Small 2018, 14, 1704493. [CrossRef]

31. Wang, Z.; Li, P.; Liu, Z.; Fan, J.; Qian, X.; He, J.; Peng, S.; He, D.; Li, M.; Gao, P. Hole selective materials and device structures of heterojunction solar cells: Recent assessment and future trends. APL Mater. 2019, 7, 110701. [CrossRef] 